\title{
EPOL: towards the fourth decade
}

\author{
Alberto Quadrio Curzio
}

Published online: 24 February 2015

(C) Springer International Publishing Switzerland 2015

\section{Three phases of "Economia politica"}

"Economia politica. Journal of Analytical and Institutional Economics" (EPOL) was founded in 1984 and since 2006 has been published entirely in English. Its international openness was established from the outset and has grown over the years both in term of authors and editorial boards. In 2015, its 32nd year of publication, the journal enters a fully international stage through Springer, a publisher with a worldwide presence, while still preserving its cultural links with il Mulino-whose logo as co-publisher will appear on the journal's cover-and keeping the Italian expression Economia politica in the title.

\section{Some features of EPOL's history}

Since the beginning and throughout its development, the journal has always taken an open, non-dogmatic approach to significant problems of theoretical and applied analysis. A more specific orientation was to contribute to a constructive relationship between economic theory and analysis on the one hand and the history of ideas and facts on the other, investigating economic issues in which historical continuity and innovation are combined. In other words, the journal has taken its inspiration from the long-term evolution of political economy, which has become one of the central social sciences thanks to its ability to place its own economic purpose between institutions and society and its method between theory and history. EPOL has always paid attention to the interplay between ideas and facts, keeping in mind

\footnotetext{
A. Quadrio Curzio ( $₫)$

Università Cattolica, Accademia Nazionale dei Lincei, Milan-Rome, Italy

e-mail: alberto.quadriocurzio@unicatt.it
} 
general and specific circumstances-including institutional situations-and trying to position them within long-term trends.

Among its many tasks EPOL has provided an important opportunity for young scholars to enter into the international political economy and economic policy debate. EPOL has also published a remarkable and growing number of articles by top level senior economists, who have greatly contributed to the journal's prestige. This is partly due to the fact that these celebrated scholars have preferred EPOL's openness to the thematic and methodological 'monolithism' of other journals. Likewise, articles have been published in EPOL by authoritative figures who have had wide-ranging institutional responsibilities, both national and international.

Thus over the years EPOL has gained increasing international significance, evidenced by its inclusion in numerous bibliographic classifications: Web of Science (WoS), Journal Citation Reports/Social Sciences Edition (Social Sciences Citation Index-IF), Social Scisearch, Scopus, SCImago Journal Rank (SJR), EconLit, RePEc, Google Scholar, Periodicals Index Online, Articoli italiani di periodici accademici (AIDA), JournalSeek, Essper, Catalogo italiano dei periodici (ACNP).

\section{Past editorial boards and supporters of EPOL}

The journal's history is intertwined with that of the economists who in various ways and at different times have supported it. To all goes my deepest thanks.

EPOL's Associate Editors have mainly been economists from Italian universities, and their number has grown over the years to 35 . Many of them have contributed to the journal's development with articles and as referees. This is also true for EPOL's Advisory Board, established in 2006 to broaden its international accreditation.

EPOL's Board of Co-Editors has evolved over the years into the stable membership of Giorgio Lunghini, Pier Carlo Nicola and Paolo Pini. Their work and vigilance has been very important and has provided an imprint of stability in the pursuit of EPOL's founding principles. Finally, the journal's Executive Editors have come and gone over time and in recent years have been Susanna Mancinelli, Giovanni Marseguerra, Guido Merzoni, Annamaria Raimondi and Luca Rossi.

A final thanks goes to the Center of Research in Economic Analysis and International Economic Development (CRANEC) of the Catholic University, Faculty of Political Sciences, which has contributed in various way to supporting EPOL's research activity. Another important contribution has also been made by Fondazione Edison (http://www.fondazioneedison.it/) and its director, Marco Fortis, both of which have supported the journal for many years.

\section{The new editorial boards of EPOL}

Beginning with this issue, the EPOL editorial boards have a new composition. As founder I remain Editor-in-Chief but supported by two new Co-Editors, Marco Fortis and Roberto Zoboli, with whom I have worked for many years and who are at the peak of their research careers. 
A team of 13 Associate Editors has been formed, made up of younger but very well accredited economists. It contains a balance of members who teach in Italian and non-Italian universities, all with strong and active international relationships. The group is also balanced from the point of view of gender. All these aspects are particularly important. Furthermore, the Associate Editors will be coordinated by Floriana Cerniglia and Sandro Montresor, who are very familiar with the journal's history and have worked with me for years.

The Advisory Board, to which belong senior excellent economists, is composed of many past members and some new members. It is characterized by pluralism across various countries and research fields. The presence of Giorgio Lunghini and Pier Carlo Nicola represent a strong element of continuity.

\section{Conclusion}

The journal thus combines tradition and innovation, being its history reflected in the senior people and its future guaranteed by the younger generation of economists. My deepest gratitude goes to all of them for having accepted the challenge of a new, fourth, decade of Economia Politica-Journal of analytical and institutional economics. The future of EPOL will depend on their choices and I believe that they are willing to meet the challenges thrown up by the economic changes and crises of the beginning of this century. After all, political economy and economic analysis should always deliver interpretations and policies aimed at improving development on a wider scale. We have every reason to believe that the articles in this first issue represent an excellent first step towards fulfilling such a program. 